\title{
Left ventricular dyssynchrony can be observed via cine CMR with use of aortic valve timing
}

\author{
Francisco Contijoch*, Kelly Rogers, Walter R Witschey, Robert C Gorman, Yuchi Han \\ From 17th Annual SCMR Scientific Sessions \\ New Orleans, LA, USA. 16-19 January 2014
}

\begin{abstract}
Background
Cine CMR is the gold standard for evaluation of left ventricular function with high spatial and temporal resolution of the EKG-gated acquisition. Measurements of dyssynchrony have previously been performed using myocardial tagging to measure relative delays in peak shortening of opposing walls. We aim to utilize non-tagged images to quantify dyssynchrony in clinical patients. This is performed by combining aortic valve timing information from a left ventricular outflow tract (LVOT) image series with segmentations of short axis datasets.
\end{abstract}

\section{Methods}

Short-axis stacks and LVOT images were acquired using standard retrospective EKG-gated bSSFP cine imaging in 63 clinical patients with a range of clinical conditions (mean EF $=44.5 \pm 19.0 \%$ ) as well as 29 patients with prolonged QRS duration. Scan parameters were as follows: in-plane resolution: $1.25-2.08 \mathrm{~mm}$, slice spacing: $8 \mathrm{~mm}$ with $2 \mathrm{~mm}$ gap, reconstructed temporal resolution: $18.2-58.8 \mathrm{~ms}$. Aortic valve opening and closing as a percentage of cardiac cycle was identified on LVOT images. Volumetric evaluation of short axis images was performed via semi-automated segmentation for all phases and all left ventricular slices (ITK-SNAP, Philadelphia PA). Dyssynchrony was measured by the standard deviation of the timing difference between each slice minimum area to aortic valve closure as expressed by the equation in Figure 1 where $\tau$ slice min corresponds to the phase at which a slice achieves its minimum area.

\section{Results}

The use of patients with prolonged QRS complexes allows for separation of measured dyssynchrony based on both EF and QRS. Patients were categorized into low $\mathrm{EF}(\leq 35 \%)$, mid EF $(35 \%<\mathrm{EF}<50 \%)$ and normal $\mathrm{EF}$ $(\geq 50 \%)$. The results are shown in Figure 1 . As has been observed using tagged-MRI, patients with low EF demonstrate higher dyssynchrony than both EF-matched controls as well as patients with long QRS but normal EF.

\section{Conclusions}

This technique allows for a slice-by-slice timing based regional evaluation of dyssynchrony. In addition, subsequent analysis of particular dyssynchronous slices could be performed to provide additional regional information.

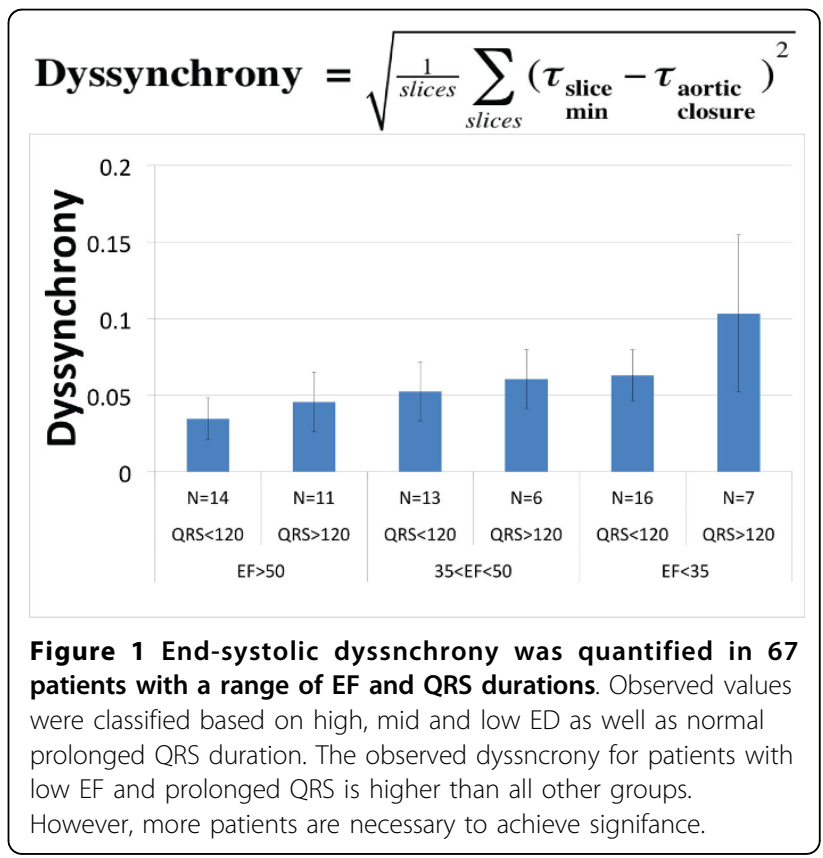

University of Pennyslvania, Philadelphia, Pennsylvania, USA 


\section{Funding}

K99-HL108157, R01-HL103723, T32HL007954, T32EB009384.

Published: 16 January 2014

doi:10.1186/1532-429X-16-S1-P243

Cite this article as: Contijoch et al:: Left ventricular dyssynchrony can be

observed via cine CMR with use of aortic valve timing. Journal of

Cardiovascular Magnetic Resonance 2014 16(Suppl 1):P243.

Submit your next manuscript to BioMed Central and take full advantage of:

- Convenient online submission

- Thorough peer review

- No space constraints or color figure charges

- Immediate publication on acceptance

- Inclusion in PubMed, CAS, Scopus and Google Scholar

- Research which is freely available for redistribution

Submit your manuscript at www.biomedcentral.com/submit
Ciomed Central 